\title{
Travessuras de um narrador romântico
}

Joelma Santana Siqueira Universidade Federal de Viçosa

\begin{abstract}
Resumo: A partir de uma breve discussão sobre as teorias do romantismo alemão, o presente artigo propõe uma leitura do romance A moreninha (1844), de Joaquim Manuel de Macedo, como exercício de escrita lúdica, em que se podem observar paralelos entre as travessuras da personagem que dá titulo à obra e as travessuras do personagem-autor.

Palavras-chave: Romantismo, Ironia romântica, A moreninha.
\end{abstract}

No ensaio "Aspectos do romantismo alemão", Anatol Rosenfeld discute a existência de duas gerações no romantismo alemão: a primeira relacionada ao pré-romantismo e a segunda ao romantismo propriamente dito e que deve muito à primeira. Além da presença de duas gerações que interagem, depreende-se de suas palavras que o romantismo alemão se formou lentamente, mas foi principalmente o pré-romantismo que repercutiu de modo vigoroso no exterior "através de obras goethianas como o romance Os padecimentos do jovem Werther, o drama medieval Goetz von Berlichingen e um fragmento do que mais tarde iria ser o Fausto, para não falar da peça Os bandoleiros, de Schiller". ' Observando que há um "certo espírito comum impregnando tanto o Sturm und Drang, como o romantismo alemão", o crítico esclarece que o

1. ROSENFELD. Texto/contexto I, p. 149. 
romantismo alemão propriamente dito "assemelha-se em certos traços bem mais aos desenvolvimentos posteriores da literatura européia, ligados a Baudelaire, ao simbolismo e à décadence literária do fin du siècle" ${ }^{2}$. E embora reconheça que ambos os momentos possuem tendências anticlássicas, não vê no romantismo alemão propriamente dito "a expansão violenta de paixões e afetos e o ímpeto irracionalista":

A visão melancólico-noturna não é típica de todos os grupos românticos, o impulso dionisíaco é apenas momento parcial de um desejo maior de harmonia e o individualismo e subjetivismo anárquicos não imperam em todos os desenvolvimentos do romantismo alemão, que se impõe lentamente, a partir de 1796 , e se extingue por volta de $1830 .{ }^{3}$

Recorrendo a textos de Schlegel e Novalis, Rosenfeld observa que os românticos posteriores à primeira geração, embora almejando uma harmonia ulterior, tenderam a acentuar as fragmentações e antinomias modernas. No que tange à literatura, destaca que a ironia, longe de ser apenas recurso retórico, é atitude fundamental, e esclarece:

Criando a obra de arte, o autor a objetiva, distanciando-se dela e do próprio eu empenhado no ato da criação; em novo ato criativo introduz dentro da obra este mesmo ato de distanciamento, e assim sucessivamente. O resultado não será decerto uma bela obra clássica, mas em compensação será sem dúvida "interessante" (nova categoria estética introduzida por F. Schlegel). A obra será "aberta", experimental, e incluirá na sua estrutura o próprio processo de sua criação. ${ }^{4}$

A imagem do romantismo alemão e, como observou Rosenfeld, do romantismo universal, na medida em que este sofreu influências alemãs, esteve com frequência relacionada ao pré-romantismo e, portanto, ao Sturm und Drang.

No Brasil, a literatura romântica define-se entre os anos de 1830 e 1880, com início próximo do fim do romantismo alemão. Com esta observação, longe de pretendermos insinuar que a defasagem de tempo tenha resultado em

2. ROSENFELD. Texto/contexto I, p. 150.

3. ROSENFELD. Texto/contexto I, p. 151.

4. ROSENFELD. Texto/contexto I, p. 164. 
cópia inferior de modelos europeus, sobretudo o francês, pretendemos apontar, seguindo sugestão de Maria Cecília Boechat, "a possibilidade de essa defasagem temporal ter funcionado como mecanismo de criação de um distanciamento crítico em relação aos modelos externos", ${ }^{5}$ a exemplo do que foi discutido pela autora no artigo "Pela tradição interna do romance brasileiro".

Frequentemente, nos estudos de nossas obras românticas dá-se ênfase ao romantismo sentimentalista com observação do subjetivismo como expressão de sentimentos e/ou expressão particular dos valores da natureza brasileira. Desconsidera-se, como Boechat nos permite observar em Paraísos artificiais, que a teoria do romantismo autorreflexivo desconstruiu "o conceito de texto como expressivismo autoral", ao trazer o eu para dentro do texto como construção ficcional e mostrar que "o 'sentimento' romântico não é pura emoção, mas sentimento ou emoção estetizados”. . A exceção é mais comumente observada nos estudos sobre a obra de Álvares de Azevedo, a exemplo do trabalho realizado por Cilaine Alves Cunha em $O$ belo e o disforme, que propõe analisar a poesia de Azevedo "como texto auto-reflexivo, que prioriza sobretudo os recursos da construção poética, a polarização entre consciência angelical e perversa", resultante "antes de um sistema poético deliberadamente concebido que de ingênuas manifestações do inconsciente". ${ }^{7}$ De um modo geral, nas leituras das obras de nossos românticos, as observações críticas muitas vezes evidenciam a expressão de sentimentalismos, a reprodução da realidade brasileira em termos de cor local ou a idealização dessa mesma realidade tendo em vista a cópia de modelos europeus. Claro que é imprescindível observar o contexto em que as obras foram produzidas e lembrar que o romantismo no Brasil "coincide com o momento decisivo da definição da nacionalidade, com propósitos expressos de reconhecer e valorizar o nosso passado histórico, embora recente, as nossas origens americanas, as tradições e legendas esboçadas, e de investigar o nosso folclore". ${ }^{8}$ O que criticamos como negativo é a redução da teoria do romantismo à poética do sentimento. Nesse sentido, Maria Cecília Boechat, em Paraísos

5. BOECHAT. Estudos de literatura brasileira, p. 42.

6. BOECHAT. Paraísos artificiais, p. 82.

7. CUNHA. O belo e o disforme, p. 26-27.

8. CANDIDO; CASTELLO. Presença da literatura brasileira. Das origens ao realismo, v. I, p. 167. 
artificiais, discutindo as figurações do romantismo brasileiro nos estudos da obra de José de Alencar, observa que se consolidou uma teoria do romantismo literário como poética centrada no eu, que não se sustenta diante da releitura da poética romântica, pois tal figuração do romantismo

é questionada por meio da recuperação da teoria do romantismo alemão, desenvolvida pelo grupo de Jena, com destaque para F. Schlegel, com a qual se demonstra a autoconsciência romântica da autonomia do texto literário. Rompendo-se com a teoria do romantismo expressivista-sentimentalista, tornou-se possível evidenciar a importância das teses românticas para a teoria da auto-reflexividade ficcional com que o movimento das vanguardas do início do século XX revolucionariam o panorama literário.?

Para exemplificarmos, vejamos uma passagem do fragmento 116 de Schlegel, publicado na revista Athenäum em 1798, no qual a poesia romântica é pensada com uma abrangência tal que o torna, de fato, um dos textos seminais nas discussões sobre o que é literatura durante e após o romantismo:

A poesia romântica é uma poesia universal progressiva. Sua destinação não é apenas reunificar todos os gêneros separados da poesia e pôr a poesia em contato com filosofia e retórica. Quer e também deve ora mesclar, ora fundir poesia e prosa, genialidade e crítica, poesia-de-arte e poesiade-natureza, tornar viva e sociável a poesia, poetizar o chiste, preencher e saturar as formas da arte com toda espécie de sólida matéria para o cultivo, e as animar pelas pulsões do humor. Abrange tudo o que seja poético, desde o sistema supremo da arte, que por sua vez contém em si muitos sistemas, até o suspiro, o beijo que a criança poetizante exala em canção sem artifício. ${ }^{10}$

Em outro fragmento presente na revista Athenäum (1798), o de número 216, Schlegel aponta a Revolução Francesa, a doutrina-da-ciência de Fichte e o Wilhelm Meister de Goethe como maiores tendências da época. Na reflexão que elabora sobre este fragmento, Andréa Werkema discute em que sentido, para Schlegel, uma visão mais abrangente da história da humanidade

9. BOECHAT. Paraísos artificiais, p. 81 .

10. SCHLEGEL. O dialeto dos fragmentos, p. 64 . 
requer a aceitação de diversos "gêneros" (ou formas) da capacidade críticoreflexiva dos homens de sua época. Levando em consideração que os fragmentos de Schlegel dialogam entre si, observa:

Os fragmentos do Athenäum buscam levar a público uma nova visão de mundo, altamente estetizada: a visão romântica. O mundo romântico admite reversibilidades infindáveis e faz da contradição uma espécie de modo de ser. Ou melhor, o mundo romântico não admite um fechamento, um pretérito perfeito, para qualquer sistema, seja no fato histórico, seja na obra filosófica ou literária.

A observação de que os fragmentos nos dão uma visão de mundo amparada na reversibilidade infinita das coisas fica exemplificada no fragmento 116 quando percebemos Schlegel finalizar com uma abertura ao estabelecer o cruzamento entre o gênero poético romântico e a própria poesia: "O gênero poético romântico é o único que é mais do que gênero e é, por assim dizer, a própria poesia: pois, num certo sentido, toda poesia é ou deve ser romântica”.

Nos estudos das obras do romantismo brasileiro, algumas vezes, abordagens excludentes das teorias românticas permitem que o crítico veja limitação no lugar de estratégia deliberadamente usada pelo escritor. Um trabalho que foge disso encontra-se no artigo " $A$ moreninha e a tradição cômica do Romantismo brasileiro", de Maria Cecília Boechat, que, a respeito do primeiro romance de Joaquim Manuel de Macedo, no lugar de ressaltar a "fidelidade ao meio", ${ }^{12}$ propôs que a veia cômica nele presente implica uma posição consciente em relação à tradição cômica europeia. Nas palavras da autora:

A moreninha constituiria uma apropriação irônica dos modelos sentimentalistas, só chegando a poder compor uma 'poética do sentimento' - a partir da qual tem sido interpretado - porque sabe rir de sua própria 'ingenuidade'. Reconhecer essa dimensão do romance, entretanto, exige que o elemento cômico seja também reconhecido como mais do que um

11. WERKEMA. Breve comentário acerca do fragmento A216, de Friedrich Schlegel, p. 52.

12. CANDIDO. Formação da literatura brasileira, v. II, p. 122. 
elemento superficial da trama: como uma estratégia eficiente e legítima da ironia romântica, tal como seria ativada pela geração poética posterior. ${ }^{13}$

O romance A moreninha, para Antônio Soares Amora, é "um pequeno romance humorístico e de atualidade" ${ }^{14}$. Escrita em Itaboraí, em apenas um mês de férias acadêmicas, informação esta presente na abertura da obra, a narrativa de pronto conquistou o público, com oito edições em vida do autor.

De acordo com Tania Serra, Amora retoma a ideia de Ferdinand Wolf sobre "o ineditismo de Macedo ao lançar na prosa de ficção brasileira os 'contrastes' estilísticos entre o 'sentimental e o humorístico', nova regra defendida particularmente para o teatro por Victor Hugo". ${ }^{15}$ O trabalho do alemão Ferdinand Wolf foi publicado pela primeira vez em Berlim em 1863. Consultando-o, observamos que o historiador, embora observe a mistura "do gracioso com o sentimental", interpreta no romance de Macedo principalmente os sentimentos dos personagens, enfatizando, por fim, o aspecto grave da narrativa:

O romance que assegurou a reputação de Macedo é "A Moreninha”, Rio de Janeiro, 1844 [...]. Macedo aqui desenvolve todas as particularidades de seu talento, o que faz dele um pintor de costumes da sociedade moderna; as cores são vivas, a pintura dos caracteres chega às vezes à caricatura, principalmente nas partes cômicas; a mistura enfim do gracioso com o sentimental é das mais felizes. Macedo gosta principalmente de descrever os primeiros germes da paixão num casal adolescente. Numerosos mal -entendidos vêm agora entravar-lhes o amor. Seu herói é ordinariamente um estudante entregue a todas as loucuras da juventude. Ele desperta o ciúme de sua amada, e que o paga com a mesma moeda. Enfim, o coração dos dois amorosos, excelente no fundo, faz valer seus direitos, explica os mal-entendidos, expia as faltas e reconhece que o amor ingênuo que ele viveu e conservou, não obstante todos os obstáculos, é agora purificado e bastará para a vida inteira. ${ }^{16}$

13. BOECHAT. A moreninha e a tradição cômica do Romantismo brasileiro, p. 128-129.

14. AMORA. A literatura brasileira, v. II, p. 213.

15. SERRA. Joaquim Manuel de Macedo ou os dois Macedos, p. 45.

16. WOLF. O Brasil literário, p. 347. 
Para Ferdinand Wolf, a ação e os sentimentos das personagens são explicados pela paixão. Esse modo de ler a obra romântica dialoga com o que Antonio Candido escreveu sobre o lastro do real presente no Romantismo e no Naturalismo brasileiros: "Com matizes mais ou menos acentuados de fatalismo, uns e outros se aplicavam em mostrar os diferentes modos por que a ação e o sentimento dos homens eram causados pelo meio, pelos antecedentes, a paixão ou o organismo." ${ }^{17}$

O sucesso oitocentista do romance e o posterior descaso da crítica para com ele se devem, muito provavelmente, à percepção restrita da visão romântica, mais próxima do que acima Rosenfeld identificou como o pré-romantismo alemão e que se pode nomear de "poética do sentimento". O romance $A$ moreninha traz o tema da fidelidade a um amor infantil que surge a partir de um encontro entre duas crianças, Augusto e Carolina, relacionado a um melodrama vulgar, ao episódio da morte de um velho de 50 anos, com um desfecho feliz para o par amoroso. No entanto, todos esses temas são passíveis de crítica dentro da obra, permitindo-nos destacá-la muito mais como "exercício lúdico de escrita", expressão de Samira Youssef Campedelli, ${ }^{18}$ ou travessura de um narrador romântico, como tentaremos demonstrar.

O romance se abre com uma cena: três jovens conversam no quarto de uma república de estudantes; eles fazem uma aposta para testar a inconstância do amor do personagem Augusto. Caso ame a uma só mulher durante 15 dias, entre 20 de julho e 20 de agosto, ele terá de escrever um romance.

Nas primeiras passagens, a narrativa acompanha o personagem Augusto. No segundo capítulo, logo após a aposta, o narrador nos informa: "São dez horas da noite. Os sinos tocaram a recolher. Augusto está só [...] / Agora ele está só”. 19 Duas vezes o narrador repete a informação de que Augusto encontrase sozinho. Observa-se a presença de Augusto em quase todos os capítulos, às vezes, de modo sorrateiro, como no capítulo XII - "Meia hora embaixo da cama" -, no qual é introduzido no gabinete das moças, após ter as calças sujas de café, e, com isso, escuta segredinhos das jovens, dos quais tira proveito em brincadeiras futuras.

17. CANDIDO. Formação da literatura brasileira, v. II, p. 99.

18. CAMPEDELLI. Entre a candura e a travessura - a esmeralda e o camafeu, p. 168.

19. MACEDO. A moreninha, p. 57. 
Além da presença de Augusto em quase todas as cenas, muitas vezes observa-se a presença também sorrateira de Carolina, a moreninha. Esse aspecto fica sugerido no modo como a moreninha é vista pelo narrador: "Deixemo-la, pois, correr, e saltar, aparecer e desaparecer ao mesmo tempo; nem à nossa pena é dado o poder de acompanhá-la, que ela é tão rápida como o pensamento". A narrativa centra-se na figura desses dois personagens, como se os dois oferecessem olhos e ouvidos ao narrador. No capítulo XVI - "O sarau", quatro amigas tramam contra Augusto no toilette onde a moreninha simula dormir, e, quando as jovens estão saindo, o narrador nos conta: "Um beijo tinha despertado um anjo, se é que o anjo realmente dormia". ${ }^{21}$ Em outro capítulo, o XIX - "Entremos nos corações", o narrador explicita a consciência de que está a acompanhar mais de perto Augusto e a moreninha na narrativa: "Vamos agora entrar no coraçãozinho de um ente bem amável, que não tem, como aquele [Augusto], uma pessoa a quem confie suas penas, e por isso sofre talvez mais. Faremos uma visita à nossa linda Moreninha". ${ }^{22}$

As descrições da moreninha, feitas a partir do modo como Augusto e o narrador onisciente a enxergam, ora bonita, ora feia, sempre travessa, no nosso entendimento, assemelha-se com a própria narrativa que estamos a ler. Isso fica mais claro neste artigo mais à frente; por enquanto, vejamos uma dessas descrições da personagem:

A Moreninha já fazia travessuras muito especiais no coração do estudante; e ele, que se acusava de haver sido injusto para com ela, agora a observava com cuidado e prazer, para, em compensação, render-lhe toda a justiça.

D. Carolina brilhava no jardim e, mais que as outras, por graças e encantos que todos sentiam e que ninguém poderia bem descrever, confessava-se que não era bela, mas jurava-se que era encantadora; alguém quereria que ela tivesse maiores olhos, porém, não havia quem resistisse à viveza de seus olhares; os que mais apaixonados fossem da doce melancolia de certos semblantes em que a languidez dos olhos e brandura de custosos risos estão exprimindo amor ardente e sentimentalismo, concordariam por força que no lindo rosto moreno de D. Carolina nada iria melhor do que o

20. MACEDO. A moreninha, p. 106.

21. MACEDO. A moreninha, p. 202.

22. MACEDO. A moreninha, p. 229. 
prazer que nele transluz e o sorriso engraçado e picante que de ordinário enfeita seus lábios: além disto, sempre em brincadora guerra com todos e em interessante contradição consigo mesma, ela a um tempo solta um ai e uma risada, graceja, fazendo-se de grave, fala, jurando não dizer palavra, apresenta-se escondendo-se, sempre quer, jamais querendo. ${ }^{23}$

A citação é longa, mas importante por apresentar um quadro das contradições da personagem que podem ser também pensadas em relação às antíteses da narrativa, e não é à toa que ambas se encontrem no nome.

Um tema recorrente no romance é o modo como os jovens vivenciam o namoro, feito à base da troca de cartas, com muitas mentiras e traições. Nesse jogo entra a figura do escravo, que leva e traz cartas. O segundo capítulo - "Fabrício em apuros" -, é exemplar disso que acabamos de observar. Nele, além de uma descrição caricatural do escravo Tobias, comparado a um "diabo de azeviche", temos a imagem negativa do negro que extorque o jovem namorador ao servir de mensageiro: "O Tobias está no caso de muitos que, grandes e excelentes parladores, são péssimos financeiros na prática. Como eles fazem ao país, faz Tobias comigo, que sempre depois de longo discurso me apresenta um deficit e pede-me um crédito suplementar". ${ }^{24}$ A obra aborda questões triviais, como o namoro dos jovens, e sérias, como a presença do escravo no seio da família. O escravo Tobias, considerado por Fabrício um "maldito crioulo", é, para a família de dona Joaninha, um "alfenim da casa”, um "São Benedito da família", e, na narrativa, um indiscreto que tira proveito do que sabe para conseguir uns trocados no leva e traz de cartas de amor entre os jovens da sociedade. O romance nos dá algumas oportunidades de ver como o narrador e os jovens da época veem e tratam o escravo, muitas vezes, chamando-o de moleque. Augusto, no início, cede seu escravo Rafael a Fabrício, e o narrador nos diz que se trata de um "querido moleque", "bom Rafael", "ao mesmo tempo o seu cozinheiro, limpa botas, cabeleireiro, moço de recados e... e tudo mais que as urgências mandavam que ele fosse". ${ }^{25}$ No entanto, como o escravo demora a retornar, Augusto pensa com frieza:

23. MACEDO. A moreninha, p. 187-188.

24. MACEDO. A moreninha, p. 68.

25. MACEDO. A moreninha, p. 58. 
- Vejam isto!... já tocou a recolher e Rafael está ainda na rua!! Se cai nas unhas de algum beleguim, não é, de certo, o Sr. Fabrício que há de pagar as despesas da Casa de Correção... Pobre do Rafael! que cavaco não dará quando the rasparem os cabelos!

Após o final de semana na ilha, de volta aos estudos, Augusto está triste, porque ama, e o narrador nos conta:

O nosso Augusto, por exemplo, está agora bronco para as lições e impertinente com tudo. Rafael é quem paga o pato; se o inocente moleque lhe apronta o chá muito cedo, apanha meia dúzia de bolos, porque quer ir vadiar pelas ruas; se no dia seguinte se demora só dez minutos, leva dois pescoções, para andar mais ligeiro. ${ }^{27}$

Essa passagem poderia até soar engraçada aos olhos dos primeiros leitores da obra. Hoje, podemos destacar que já no primeiro romance de Macedo há olhares diversificados para a figura do escravo que, ora é visto como um algoz (o caso de Tobias), como uma vítima (o caso de Rafael) e como uma pessoa estimada (o caso de Paula, a ama de Carolina), fazendo-nos pensar que a discussão sobre a presença do escravo na obra do escritor não deve se concentrar apenas em torno de sua obra mais tardia, em especial As vítimas algozes (1869).

A respeito da variedade de assuntos presente no romance, ao considerar a recepção da obra pelos primeiros leitores, Amora escreveu:

Quanto ao desconcertante do livro, para os primeiros leitores, deve este ter resultado do frequente jogo de contrastes, entre o sentimental e o humorístico, o que não possibilitava ao leitor fixar-se em determinada predisposição de leitura; e ainda na variedade desordenada de seus elementos: a intriga amorosa, as observações sobre "cousas da moda" e sobre tipos humanos; a crítica social e política; uma lenda indígena; descrições de ambientes e reflexões sobre o amor, a vida da Corte e da província, e as fraquezas humanas. ${ }^{28}$

26. MACEDO. A moreninha, p. 58.

27. MACEDO. A moreninha, p. 221.

28. AMORA. A literatura brasileira, v. II, p. 218. 
O crítico considera que as convenções do gênero romance, apesar de preverem a multiplicidade de elementos, não abdicavam de uma estrutura orgânica e, nesse sentido, o romance de Macedo, "pela sua desordem interna e pelo seu 'realismo', era, à evidência, o oposto de tudo isso: tinha, portanto, de chocar e desconcertar o leitor." 29

Não entraremos no mérito da discussão sobre a recepção do romance por seus primeiros leitores. Atentando para a autorreflexividade, propomos que a estrutura orgânica pode ser percebida nas anotações do travesso narrador, que o próprio Amora soube ver ao se reportar às palavras presentes na abertura do romance, quando repetiu que Macedo quis fazer umas 'travessuras' literárias que entretivessem e divertissem os leitores.

O sentimento amoroso é constantemente posto à prova na narrativa por meio da leitura das cartas que os jovens escrevem uns para os outros com juras de amor que não passam de mentiras para a conquista do par; na descrição do sistema calculista de Fabrício, que não namora moça de sobrado; na análise fria de Leopoldo sobre os sentimentos das moças da Corte, tão diferentes das moças da roça; e na própria voz do narrador que muitas vezes nos faz rir do amor. Vejamos a réplica do personagem Fabrício ao conselho de Augusto para que o amigo respeite e cultive o sentimento que o liga à jovem Joaninha:

- Bravo! bravo! foi muito bem respondido, mas, palavra de honra, que tenho dó de ti! Vejo que em matérias da natureza da de que tratamos estás tão atrasado como eu, em fazer sonetos. Apesar de todo o teu romantismo ou, talvez, principalmente por causa dele, não vês o que se passa a duas polegadas do nariz. Pois meu amigo, quero te dizer: a teoria do amor do nosso tempo aplaude e aconselha o meu procedimento; tu verás que eu estou na regra, porque as moças têm ultimamente tomado por mote de todos os seus apaixonados extremos, ternos afetos e gratos requebros, estes três infinitos de verbos: - iscar, pescar e casar. Ora, bem vês que, para contrabalançar tão parlamentares e viscosas disposições, nós, os rapazes, não podíamos deixar de inscrever por divisa em nossos escudos os infinitos desses três outros verbos: fingir, rir e fugir. Portanto, segue-se que estou encadernado nos axiomas da ciência. ${ }^{30}$

29. AMORA. A literatura brasileira, v. II, p. 218.

30. MACEDO. A moreninha, p. 84 . 
A fala de Fabrício ilustra uma análise fria do namoro puramente casamenteiro, que ele ironicamente chama de "teoria do amor do nosso tempo". Em outras situações, é o narrador quem nos faz rir do amor, do personagem que ama e, de quebra, da própria narrativa:

Ora, o tal bichinho chamado amor é capaz de amoldar seus escolhidos a todas as circunstâncias e de obrigá-los a fazer quanta parvoíce há neste mundo. O amor faz o velho criança, o sábio doido, o rei humilde, cativo; faz mesmo, às vezes, com que o feio pareça bonito e o grão de areia um gigante. O amor seria capaz de obrigar um coxo a brincar "o tempo será", a um surdo "o companheiro companhão" e a um cego o "procura quem te deu". O amor foi inventor das cabeleiras, dos dentes postiços que... mas, alto lá! que isto é bulir com muita gente; enfim, o amor está fazendo um estudante do quinto ano de medicina passar um dia inteiro brincando com bonecas.

Na passagem abaixo, observa-se que o distanciamento da matéria narrada é ironizado por um narrador que se apresenta como quem acaba de ver e ouvir uma cena da qual não participa, referindo-se tanto ao autor quanto ao personagem como um outro (ele), quando são um só, o Augusto, personagemautor:

São seis horas da manhã e todos dormem ainda a sono solto.

Um autor pode entrar em toda parte e, pois... Não, não, alto lá! no gabinete das moças, não senhor, no dos rapazes, ainda bem. A porta está aberta. Eis os quatro estudantes estirados numa larga esteira; e como roncam! Mas que faz o nosso Augusto? Ri-se, murmura frases imperceptíveis, suspira... Então que é isso lá?... dá um beijo em Fabrício, acorda espantado e ainda em cima empurra cruelmente o mesmo a quem acaba de beijar... ${ }^{32}$

Ironicamente, o narrador está gracejando sobre o processo de composição da narrativa que estamos lendo, pois o autor é o personagem que esteve escondido no gabinete das moças. Nesse sentido, a obra parece apontar sorrateiramente para o próprio processo de criação, permitindo-nos observar a obra aberta, experimental, referida por Rosenfeld.

31. MACEDO. A moreninha, p. 246-247.

32. MACEDO. A moreninha. p. 186. 
No capítulo XVIII - "Achou quem o tosquiasse", Carolina brinca de adivinhar segredos, como Augusto brincou antes com as jovens de quem ouviu conversa enquanto esteve debaixo da cama. Desta vez, é a moreninha quem finge adivinhar segredos que ela sorrateiramente ouviu, por exemplo, escutando Augusto contar para sua avó na gruta. O diálogo abaixo entre os dois personagens permite-nos destacar mais uma ironia na narrativa, ao observarmos Augusto explicitar uma concepção de narrativa romântica associada à beleza da desordem.

- Pelo amor de seus belos olhos, minha senhora, vamos antes ao que eu não sei, vamos ao meu futuro.

- Sois sobejamente sôfrego! não vedes como isso vai contra a boa ordem da narração?

- Mas a desordem é hoje a moda! o belo está no desconcerto; o sublime no que se não entende; o feio é só o que podemos compreender: isto é romântico; queira ser romântica, vamos ao meu futuro. ${ }^{33}$

A referência à desordem não é gratuita. A narrativa começa com uma aposta a ser paga com um romance a ser escrito por Felipe ou Augusto. Lemos todo o desenrolar da narrativa e, ao final, descobrimos que estivemos a ler o romance fruto da aposta, uma vez que nas últimas linhas somos informados de que o romance está pronto e se intitula $A$ moreninha, fazendo o fim e o começo se encontrarem por meio de uma grande reversibilidade: Augusto perder (a aposta) ganhando (a moreninha).

Há muitas referências ao romantismo na narrativa, que é contraditoriamente ironizado e endossado. É o próprio narrador quem observa que a seriedade do amor é para quem ama e não para quem reflete sobre o tema: "que mancebo há aí, de dezesseis anos por diante, que não tenha experimentado esses doces enleios, tão leves para a reflexão e tão graves e apreciáveis para a imaginação de quem ama?", Nas palavras de abertura do romance, Macedo informou que sua motivação não veio do amor, pois se este "buliçoso" estivesse "a fazer cócegas no coração", bem sabia ele que mais proveitoso lhe "seria gastar

33. MACEDO. A moreninha, p. 217.

34. MACEDO. A moreninha, p. 242. 
meia dúzia de semanas aprendendo numa sala de dança, do que velar trinta noites garatujando o que por aí vai". ${ }^{35}$

Umas das maiores ironias do romance está em Augusto negar o amor do passado para obter o amor do presente, sendo que um e outro são um só. No último capítulo - "A esmeralda e o camafeu", quando Carolina pergunta-lhe sobre o juramento de amor do passado, ele diz que foi juramento de criança; e quando ela pergunta por que deu o breve (a prova do amor) à menina no passado, ele, novamente, ressalta que era um louco, uma criança. O amor não parece ser coisa para ser apenas levada a sério, pois se o do passado de Augusto o fosse, o de seu presente não poderia ser, e, ao mesmo tempo, o amor parece coisa séria, pois o do presente, em certa medida, é o do passado. Visando obter o amor de Carolina no presente, duas vezes Augusto nega o amor que sentiu no passado, dizendo que se reencontrasse a menina a quem jurou amor pediria perdão, devolveria a prenda de amor e diria que agora ama outra. As palavras de Augusto são cortadas por esta observação do narrador: "A cena se estava tornando patética; ambos choravam e só passados alguns instantes a inexplicável Moreninha pôde falar e responder ao triste estudante". Carolina manda Augusto procurar a menina do passado e, se ela concordar com o pedido de perdão de Augusto, ele pode voltar que ela, a moreninha, será sua esposa. Trata-se de uma brincadeira, já que a menina do passado e a moreninha são a mesma pessoa. É preciso que a menina do passado aceite a recusa de Augusto para que a do presente aceite o amor de agora. Quando, finalmente, a moreninha entrega a Augusto um camafeu que lhe foi dado no passado por um menino, temos a constância na inconstância. O último capítulo termina com a fala de Carolina: "- Ah! minha boa avó! respondeu a travessa Moreninha ingenuamente: nós éramos conhecidos antigos."

Logo em seguida vem o Epílogo no qual se lê que é o dia 20 de agosto, um mês depois do início da narrativa e da aposta. Augusto está noivo de Carolina, a moreninha, mas o romance não termina em casamento e sim com esta referência à própria narrativa:

- Minha boa avó, exclamou Felipe, isto quer dizer que Augusto deve-me um romance.

35. MACEDO. A moreninha, p. 43.

36. MACEDO. A moreninha, p. 268.

37. MACEDO. A moreninha, p. 269. 
- Já está pronto, respondeu o noivo.

- Como se intitula?

$-A$ Moreninha. ${ }^{38}$

A moreninha é personagem e título da narrativa, ambas se aproximam mais do que apenas no nome. De ambas poderíamos dizer o que Augusto disse de Carolina: "é, na verdade, travessa, mas a cada travessura, ajunta tanta graça, que tudo se lhe perdoa." " Quando o narrador diz que "ela não para: o movimento é a sua vida; esteve no jardim e em toda parte [...] Travessa menina!... Porém, ela tempera todas as travessuras com tanta viveza, graça e espírito...", lembra-nos palavras do autor presentes na abertura do romance, pois Macedo informa que passou "trinta dias garatujando" com "imaginação traquinas" uma obra "travessa":

Dir-me-ão que o ser a minha imaginação traquinas não é um motivo plausível para vir eu maçar a paciência dos leitores com uma composição balda de merecimento e cheia de irregularidades e defeitos; mas o que querem? quem escreve olha a sua obra como seu filho e todo o mundo sabe que o pai acha sempre graça e bondades na querida prole.

[...] A Moreninha não é a única filha que possuo: tem três irmãos que pretendo educar com esmero; o mesmo faria a ela; porém, esta menina saiu tão travessa, tão impertinente, que não pude mais sofrê-la no seu berço de carteira e, para ver-me livre dela, venho depositá-la nas mãos do Público, de cuja benignidade e paciência tenho ouvido grandes elogios.

Nesse primeiro romance de Macedo não é possível fixarmo-nos no sentimento amoroso sem rirmos dele. A imaginação traquina do narrador não nos permite. O tema do amor recebeu um tratamento travesso que nos faz pensar na ideia de Schlegel sobre o que é a ironia: "consciência clara da eterna agilidade, do caos infinitamente pleno". ${ }^{42}$ Propomos, então, que a obra A moreninha é uma importante realização artística na história do romance brasileiro.

38. MACEDO. A moreninha, p. 271.

39. MACEDO. A moreninha, p. 180.

40. MACEDO. A moreninha, p. 150.

41. MACEDO. A moreninha, p. 44.

42. SCHLEGEL. O dialeto do fragmento, p. 153. 


\section{Pranks of a romantic narrator}

\section{Abstract: Supported by a brief discussion about German Romanticism theories, this article proposes a reading of the novel A moreninha, by Joaquim Manuel de Macedo, as a fun writing exercise in which one can notice parallels between the pranks of the character who entitles the work and the pranks of the author-character.}

Keywords: Romanticism, Romantic irony, A moreninha.

$$
\text { Referências }
$$

AMORA, Antônio Soares. A literatura brasileira - O romantismo (1833-1838/1878-1881). 4 ed. São Paulo: Cultrix, 1973. v. II.

BOECHAT, Maria Cecília. Pela tradição interna do romance brasileiro. In: BASTOS, Alcmeno et al. Estudos de literatura brasileira. Belo Horizonte: Faculdade de Letras da UFMG, 2008. p. 37-51.

BOECHAT, Maria Cecília. Paraísos artificiais: o romantismo de José de Alencar e sua recepção crítica. Belo Horizonte: Editora da UFMG, 2003.

BOECHAT, Maria Cecília. A moreninha e a tradição cômica do romance. Revista do Centro de Estudos Portugueses, UFMG, Belo Horizonte, v. 25, p. 123-129, 2005.

CAMPEDELLI, Samira Youssef. Entre a candura e a travessura. In: MACEDO, Joaquim Manuel de. A moreninha. São Paulo: Círculo do Livro, 1987. p. 163-169.

CANDIDO, Antonio. Formação da literatura brasileira: momentos decisivos. 6 ed. Belo Horizonte: Itatiaia, 2000. v. II.

CANDIDO, Antonio; CASTELLO, José Aderaldo. Presença da literatura brasileira. Das origens ao realismo. 12 ed. Rio de Janeiro: Bertrand Brasil, 2005. v. I.

CUNHA, Cilaine Alves. O belo e o disforme. São Paulo: Edusp, 1998.

MACEDO, Joaquim Manuel de. A moreninha. Ed. crítica de Tania Serra. Rio de Janeiro: Lacerda, 1997.

ROSENFELD, Anatol. Aspectos do romantismo alemão. In: Texto/contexto I. 5 ed. São Paulo: Perspectiva, 1996.

SCHLEGEL, Friedrich. O dialeto dos fragmentos. Trad. Márcio Suzuki. São Paulo: Iluminuras, 1997.

SERRA, Tania Rebelo Costa. Joaquim Manuel de Macedo ou os dois Macedos. Brasília: Editora da Universidade de Brasília, 2004.

WERKEMA, Andréa Sirihal. Breve comentário acerca do fragmento A216, de Friedrich Schlegel. Eutomia, Recife, v. 8, p. 49-54, dez. 2011.

WOLF, Ferdinand. O Brasil literário: história da literatura brasileira. Trad. Jamil Almansur Haddad. São Paulo: Companhia Editora Nacional, 1955. 